\title{
Grammar instruction through multinational telecollaboration for pre-service teachers
}

\author{
Aleksandra Wach \\ Adam Mickiewicz University, Poland (waleks@amu.edu.pl) \\ De Zhang \\ Bethel University, United States (dzhang@bethel.edu) \\ Kristen Nichols-Besel \\ Bethel University, United States (kmn39985@bethel.edu)
}

\begin{abstract}
Recognizing the importance of multinational telecollaboration and form-focused instruction in computerassisted language learning teacher education, this article investigates teaching English grammar through a seven-week-long telecollaborative project with 41 pre-service language teachers from the United States (US), Poland, and China. The telecollaboration was a pedagogical intervention in which the US participants taught grammar to their non-native-speaker peers. Specifically, the study aimed to trace pre-service teachers' grammar instruction techniques applied in the communication-oriented context of online exchanges and responses to this instruction, the grammar forms attended to in the exchanges, and the participants' evaluations of the usefulness of telecollaboration for teaching and learning grammar. Utilizing data from the participants' emails and results of a post-project survey, this mixed methods study reveals that (1) the implicit technique of modeling was the most frequently applied; (2) the grammatical forms used in both implicit and explicit teaching reflected the communicative orientation of the exchanges; (3) the levels of uptake (i.e. attempts to follow the models provided in the input), and the forms attended to by the learners, reflected their proficiency levels and linguistic background; and (4) participants reported positive opinions about the value of telecollaboration in grammar instruction and in teacher training. The data thus underscore the benefits of online exchanges in giving prospective teachers hands-on experience with communicative grammar teaching.
\end{abstract}

Keywords: telecollaboration; grammar instruction; pre-service teachers; multinational; teacher education

\section{Introduction}

Telecollaborative exchanges, by creating communicative discourse options with participants from beyond the classroom, support second and foreign language (L2) learning and teaching in numerous ways. Among other benefits, research has shown that telecollaboration fosters the development of learners' linguistic skills and performance (Jin, 2013; Sauro, 2009), and has revealed its potential in aiding teacher education (Dooly \& Sadler, 2013; Vinagre, 2017). The positive influence of telecollaboration on L2 learning and teacher development is often accounted for by sociocultural and interactionist L2 learning theories (Dooly, 2017; Heift \& Vyatkina, 2017).

Within the sociocultural perspective, teachers' cognition develops through social interactions, with the important mediating role of other people (Johnson, 2009; Johnson \& Golombek, 2020).

Cite this article: Wach, A., Zhang, D. \& Nichols-Besel, K. (2022). Grammar instruction through multinational telecollaboration for pre-service teachers. ReCALL 34(1): 4-20. https://doi.org/10.1017/S0958344021000112 
Engaging teachers in authentic, goal-oriented activities to help them internalize academic concepts and creating "structured mediational spaces" where they can develop their teaching skills are thus among the main premises on which sociocultural teacher education is based (Johnson \& Golombek, 2020: 119). Consequently, telecollaboration, which involves teachers in online exchanges with peers from another culture, is a valuable option for complementing L2 teacher training courses. Research on such instructional options has revealed pre- and in-service teachers' improved collaboration and teaching skills, increased reflectivity, intercultural awareness and digital competence, as well as enhanced satisfaction and confidence (Angelova \& Zhao, 2016; Dooly \& Sadler, 2013; Rienties, Lewis, O’Dowd, Rets \& Rogaten, 2020).

From the sociocultural perspective on the development of L2 grammar, learning is a social, situation-oriented process, enhanced by exposure to input in a culturally contextualized activity (e.g. by observing the linguistic behavior of others) (Lantolf, Thorne \& Poehner, 2015). The crucial role of input, modified through meaning negotiation and thus optimally adjusted to learners' L2 level and communicative needs, is also among the main premises of interactionist theory (Gass, 1997). Telecollaboration, especially when conducted in an asynchronous mode, offers opportunities for learners to pay closer attention to input and to monitor their output (Heift \& Vyatkina, 2017; Ware \& Pérez Cañado, 2007). These promising assumptions have been confirmed by research on the effectiveness of corrective feedback (CF) on the development of learners' L2 grammar in telecollaboration (Vinagre \& Muñoz, 2011; Ware \& O’Dowd, 2008) and learners' positive opinions of the value of such practice (Akiyama, 2017; Dussias, 2006; Jin, 2013). Telecollaboration for L2 grammar development can also be used in L2 teacher training (Angelova \& Zhao, 2016; Samburskiy \& Quah, 2014), with the aim of enhancing pre-service teachers' grammatical and pedagogical knowledge. However, research into such options in teacher training has been scant in the literature.

The telecollaboration reported in our study was part of the participants' pre-service teacher education courses. Hence, in congruence with sociocultural theory, which stresses the socially situated nature of learning to teach, its pedagogical aim was to give pre-service teachers hands-on experience in grammar-oriented telecollaboration as instructors and/or learners. In comparison to previous research, our study is novel in two ways. First, the telecollaboration was multicultural and intercontinental, involving participants from the United States (US), Poland, and China, where the native-speaker (NS) students acted as interaction partners, but also as L2 experts and instructors, and the non-native-speaker (NNS) students, besides being interaction partners, took the role of learners. Second, unlike most studies on grammar in online exchanges, which almost exclusively focus on $\mathrm{CF}$, it offers a broader perspective of grammar instruction, exploring the ways that grammar was taught by NS pre-service teachers to their NNS peers, the responses that the various teaching techniques elicited, and the grammatical forms that were attended to in the exchanges.

\section{Literature review}

\subsection{Telecollaboration for language teacher education}

Telecollaboration, defined as "the process of communicating and working (a/synchronously) together with other people or groups from different locations through online or digital tools" (Dooly \& Sadler, 2020: 5), has emerged as an exciting and challenging area in the field of computer-assisted language learning. Various terms for this instructional option have been used, such as virtual exchange, online intercultural exchange, or eTandem (Dooly \& O’Dowd, 2018; O'Dowd, 2018). Regardless of the terminology, the key elements of telecollaboration are language(s), learners, electronically/digitally mediated communication, collaborative and social interaction, dialogue, and intercultural exchange (Dooly, 2017), all of which are crucial concepts in contemporary L 2 instruction and, by extension, in training competent L2 teachers. 
O'Dowd (2015) discusses the competences that a teacher needs in order to conduct telecollaborative activities: well-developed organizational, pedagogical, and digital skills, as well as the appropriate attitudes and beliefs. These include a belief that culture is ingrained in L2 learning, interest in and openness to novel tasks offered by partners, and willingness to assume new roles. Therefore, engaging pre-service teachers in telecollaboration projects is a good way of preparing them for the challenges of implementing technology in their own teaching in the future. In this way, telecollaboration embodies the principles of truly communicative and interactive "cognitive apprenticeship" (Dooly \& Sadler, 2013: 5), giving pre-service teachers experience in social and professional interactions with their counterparts from teacher education courses in other countries.

Research on telecollaboration in pre-service teacher education underscores its effects on the developing social and pedagogical competences. For example, Dooly and Sadler's (2013) findings showed that telecollaboration created a digital space for the pre-service teachers to exchange opinions and experiences, leading toward an emergent feeling of a community of practice among the participants, and contributing to their enhanced reflectivity and critical thinking. Similarly, Kurek and Müller-Hartmann (2019) found that various forms of communities of inquiry, characterized by self- and co-regulation behaviors and cognitive engagement, were developed in the course of a series of blended-format online exchanges between Polish and German pre-service teachers. Vinagre's (2017) research project focused on the development of the conceptual and procedural competencies required in conducting effective telecollaboration, and provided experiential training for pre- and in-service teachers located in different countries.

Rienties et al.'s (2020) large-scale experimental study investigated the impact of telecollaboration on pre-service teachers' technological pedagogical content knowledge (TPACK), which involves understanding how technology supports teachers' knowledge of the content and pedagogical skills in providing effective instruction (Mishra \& Koehler, 2006). A sample of 622 pre-service teachers from 16 countries participated in the study. The results indicated that although the students benefited from the experience, the telecollaboration participants' gains in technological and pedagogical knowledge were not significantly higher than in the control condition. The researchers concluded that a number of factors, including the organization of an online exchange and the participants' motivation, may influence its effectiveness. However, telecollaboration led to a significantly higher increase in the perceived L2 competence, and this score was positively correlated with the TPACK skills.

\subsection{Telecollaboration for grammar instruction}

The communicative and interactive nature of telecollaboration aligns with recent recommendations for teaching L2 grammar. Larsen-Freeman (2014: 258) defines grammar as "a system of lexicogrammatical patterns that are used to make meaning in appropriate ways," and cautions that effective instruction encompasses the form, semantics, and pragmatics of L2 structures to allow an accurate, meaningful, and appropriate use of language. As noted by Ellis (2014), effective grammar instruction can be implemented through explicit teaching, which usually involves techniques such as rule presentation and metalinguistic explanation, and implicit teaching, which attracts learners' attention to form while they are primarily concentrated on meaning. According to Lantolf et al. (2015), mediation through student-teacher (i.e. novice-expert) interaction, closely related to the actual emergent need, is a cornerstone of the sociocultural theory of L2 development. This mediation can take different forms, but it works best if "provided following a continuum that begins with implicit hints and moves toward explicit correction as necessary" (Lantolf et al., 2015: 212), while being embedded in social context and involving culturally organized activity. Such conditions can be effectively provided by telecollaboration.

Within the interactionist orientation, grammar is learned through exposure to L2 input, engagement in interaction, and L2 production. Input is most beneficial if interactionally modified 
- that is, adjusted to learners' level and communicative needs (Gass, 1997; Long, 1996). Involvement in telecollaboration, by providing both positive and negative evidence of L2 use, can stimulate learners' noticing of structures in the input, which, according to Schmidt's (1990) noticing hypothesis, is an important precondition to learning. Sharwood Smith (2014) distinguishes between perceptual (e.g. flooding), conceptual (e.g. explanations), and affective (e.g. contextualization influencing learners' emotions and values) types of input enhancement, all potentially contributing to learners paying attention to forms.

Research focusing specifically on grammar instruction in telecollaborative contexts has been scant; most studies describe exchanges with a broader scope that also resulted in learning grammar. For example, Dussias (2006) found positive effects of the intercultural dimension factor on learners' grammar (various structures in L2 Spanish) in terms of gains in oral production tasks; in Jin's (2013) study, learning grammar was investigated alongside reading skills and lexical development in L2 Chinese. Chen and Eslami (2013) noted the effects of incidental focus on form in telecollaborative live chats on learners' uptake in grammar and vocabulary (various structures and items). The studies with a more specific focus on grammar development typically look at the effects and/or learners' perceptions of CF provided by NS partners in eTandem setups (e.g. Akiyama, 2017; Vinagre \& Muñoz, 2011; Ware \& O'Dowd, 2008). In some of these studies, pre-selected grammar structures were targeted. In Sauro's (2009) investigation, in which participants provided various types of CF on the zero article in English, metalinguistic feedback proved more effective than recasts. Vinagre and Muñoz's (2011) German and Spanish NS participants addressed grammatical, lexical, spelling, and discourse errors in their keypals' emails. The most frequently corrected structures were the most problematic ones for L2 learners: concordance and prepositions (in both languages), word order (in German), and verb tense (in Spanish).

The use of telecollaboration for providing L2 grammar instruction with the aim of developing pre-service teachers' competence has been a recent, and so far insufficiently addressed, strand of research. In Sauro's (2013) study, US-based teacher trainees gave CF to English as a foreign language (EFL) learners on their writing in a text chat. Three structures were targeted: the zero article, subject-verb agreement, and apostrophe for possessives. Recasts, enhancements, explicit corrections, and metalinguistic feedback were given. Uptake was limited, however, by the activity (text chat) and by the learners' copying and pasting pre-prepared chunks. Samburskiy and Quah (2014) investigated the practices of giving CF on lexical and grammatical errors by NS novice teachers to intermediate English learners, finding that implicit forms of CF, recast and textual enhancement, were most frequently used. Various structures and forms, depending on what errors were made, were attended to, with vocabulary corrected more often than grammar. In Angelova and Zhao's (2016) study, NS pre- and in-service teachers gave CF to NNS pre-service teachers on the mistakes detected in their essays. Some uptake was observed on a number of grammatical structures, such as relative clauses, gerunds, run-on sentences, conjunctions, subject-verb agreement, compound sentences, and so on. In addition, the NS participants admitted that their teaching skills had improved. In the large-scale study (involving 1,018 participants from 16 European countries) reported by the EVALUATE Group (2019), grammar was not taught; instead, several teacher training institutions from different countries collaborated in English as a lingua franca, aiming to explore the impact of telecollaboration on different areas of pre-service teachers' competence. In the reflective journals, the participants acknowledged that their grammatical competence had improved, as, for example, they used more complex language. Moreover, they recounted the opportunities for practicing their instructional techniques and skills, as well as for enhancing their confidence as L2 users and providers of CF. Interestingly, some researchers (Sauro, 2013; Vinagre \& Muñoz, 2011; Ware \& O’Dowd, 2008) noted considerable differences between various groups of telecollaboration participants in terms of their learning cultures, experiences with the L2, preferences, and metalinguistic knowledge. Such differences affect the dynamics of interaction and reveal a need to compare groups before any conclusions are drawn. 
Telecollaboration in teacher education with an orientation toward grammar teaching has not received sufficient attention from researchers. We aim to bridge this gap by reporting the results of a study that investigated pre-service teachers' behavior and opinions in relation to L2 grammar instruction in the context of a multinational asynchronous telecollaboration project. The following research questions were formulated:

1. What grammar teaching techniques were used in the email exchanges by the NS pre-service teachers, and what responses did they stimulate?

2. Which grammatical structures were targeted by the NS participants in their instruction, and which appeared in the NNS participants' responses to instruction?

3. What were the participants' perceptions about the value of telecollaboration for learning L2 grammar and for their teacher training, and were there differences in this respect between the nationality groups?

\section{Methodology}

\subsection{Context and participants}

The sample $(N=41)$ consisted of pre-service language teachers from three different countries: the US $(n=14)$, Poland $(n=13)$, and China $(n=14)$. The US participants, NS of English with experience of learning at least one foreign language, were students at a small liberal arts college in the Midwest, majoring in linguistics or TESOL (teaching English to speakers of other languages). The Polish students were English majors with a minor in TEFL (teaching English as a foreign language) from a big comprehensive university in Poland. The Chinese students majored in TCSL (teaching Chinese as a second language) at a large comprehensive university in China. All NNS participants had been learning English since primary school; however, because of the different majors, the proficiency level was upper-intermediate in the Polish and intermediate in the Chinese groups. As telecollaboration is inherently about intercultural interaction, involving culturally varied contexts (three countries from three different continents) was assumed to stimulate the participants' interest and, consequently, their engagement in the interactions. Although the cultural and educational contexts were different, the common denominator for all participants was that they were all pre-service teachers interested in teaching foreign or second languages.

The telecollaboration was designed as part of the coursework in a required English grammar course for the US students, most of whom would teach English as a second language in K-12 settings in the US. Their goal for this project was thus to practice providing grammar instruction to NNS through asynchronous computer-mediated communication (CMC). The US participants' task was to select and apply the instructional techniques they found appropriate in the communicative setting of the exchanges, teaching grammatical structures of their choice. They were encouraged to try out various ways of teaching grammar they had learned in the course. The Polish and Chinese participants were told that in the course of the telecollaboration, alongside socializing and exchanging information, they would receive grammar instruction from the US students. It was assumed that engaging prospective teachers in authentic use of English in a multinational telecollaboration would give them valuable experience in learning and teaching L2 grammar in online interactions.

This design of the telecollaboration was rather asymmetrical, with the US participants serving as language experts and taking on the "teacher" role, whereas the Polish and Chinese participants, less competent users of English, assumed the roles of "learners" (issues of power distribution and NS/NNS identities in interaction are discussed by Helm, 2018, and Liddicoat, 2016). This imbalance of power was justified in the context of the study, which focused on grammar instruction and language accuracy in the exchanges, and thus deliberately involved the NS/ NNS arrangement of the groups. Similar NS/NNS setups have also been employed in other studies 
focusing specifically on form-focused teaching in online interaction (e.g. Angelova \& Zhao, 2016; Samburskiy \& Quah, 2014; Sauro, 2013).

\subsection{Data collection}

Data were collected through email exchanges and a survey. Email was chosen as the interaction tool for two reasons: the different time zones across the three continents necessitated the use of an asynchronous communication mode, and the availability of other tools was limited to some of the participants. The students were arbitrarily put into seven groups of five or six, each consisting of one or two students from each nationality. The email exchanges lasted for seven weeks. The topics for the interactions mainly concerned general cultural issues such as family, food, holidays, and so on (see Appendix), and were selected by the US students out of a collection of topics provided by the second author. In some situations, however, the Chinese and Polish students initiated a topic, which was taken up by the US students. The function of the discussion topics was to stimulate interactions, primarily to create context for the teaching of grammar, but also, which is quite natural in telecollaboration, to foster intercultural competence - this aspect, however, was not embraced by the present analysis.

After the email exchange, an online survey was administered using the software Qualtrics. Apart from a demographic section, the survey consisted of 15 Likert-type items, 10 of which were analyzed in this study, and one open-ended question asking the participants to share their suggestions for improving the telecollaborative project. Thirty-nine out of 41 participants filled in the closed-ended items, and 30 of them answered the open-ended question.

The 10 Likert-type items in the survey fell within two scales: one related to the respondents' $(N=39)$ evaluations of telecollaboration in learning and teaching L2 grammar (six items), and the other to their opinions about the usefulness of telecollaboration for their L2 teacher training (four items). The reliability (Cronbach's alpha) levels of the thematic scales were $\alpha=0.808$ and $\alpha=$ 0.782 , respectively. The respondents marked their answers on a 5-point scale according to the following key: 1 = "strongly disagree," 2 = "somewhat disagree," 3 = "neither agree nor disagree," $4=$ "somewhat agree," and $5=$ "strongly agree."

\subsection{Data analysis}

\subsubsection{Qualitative analyses}

The qualitative data from both the email exchanges and the open-ended survey question underwent a content analysis in which units of data were determined in relation to the research questions and assigned to categories (Merriam \& Tisdell, 2016). The analysis methods were inductive, in that the themes emerged from the data, and iterative, in that multiple passes through the data were made before settling on the final list of codes (Patton, 2002).

A total of 277 emails were collected through the exchanges. An initial list of codes, generated by the first author, was then revised and verified by all authors. Agreement was reached through Skype meetings and collaboration on Google documents in terms of codes, categories, and emerging themes.

Three themes emerged: types of teaching, response to instruction, and participants' opinions. Types of teaching included six codes: modeling, explicit feedback, task, examples, metalinguistic instruction, and grammar material. Response to instruction included three codes: uptake, attempted uptake, and lack of uptake. It should be noted that the label "uptake" was used to refer to instances of learners incorporating the target grammatical structure in response to instruction; thus, the scope of the term is broader than the common understanding of uptake as a learner's reaction to CF (Lyster \& Ranta, 1997). In the analysis, only those utterances that followed a given instance of instruction and clearly showed an NNS student's correction or were a direct reflection of the model utterance were counted as instances of "uptake." 
Participants' opinions included four codes: opinion about telecollaboration, opinion about L2 learning, self-evaluation, and suggestions for effective learning. Within the coded chunks denoting types of teaching and response to instruction, a subsequent analysis involved a detection of the grammatical structures that appeared in the emails and the quantification of the c-units, which are phrases with a communicative meaning (Crookes, 1990) that contained these structures. For example, the single sentence "Looking forward to hearing from you!" was counted as one c-unit, but in the sentence "What languages do you guys speak, or what languages have you learned?" two c-units were distinguished, one for each coordinate clause.

The analysis of the open-ended survey responses was conducted by the second and third authors, who read through them independently, highlighted units of data with the third research question in mind, and determined descriptors. These were grouped into five main themes: accountability, expectations/awareness, grouping, platform/modality, topics.

\subsubsection{Quantitative analyses}

The quantitative data from the Likert-type survey items were analyzed with IBM SPSS (Version $25)$. The significance level $(p)$ was set at .05 for all statistical analyses. First, descriptive statistics were calculated for each subsample. Next, the data underwent non-parametric statistical analyses because of their non-normal distribution. A Kruskal-Wallis test was applied to determine whether the differences between the scores of the three groups were statistically significant. This was followed by a Mann-Whitney $U$ test, run in order to perform inter-group comparisons. Additionally, effect size $r$ was calculated to further confirm the relationship between variables (Larson-Hall, 2010).

\section{Results}

\subsection{Email exchanges}

\subsubsection{Types of teaching}

The theme types of teaching refers to the grammar teaching techniques the US students used. Table 1 includes, for each code, a definition, an example from the transcripts, ${ }^{1}$ the total number of times counted, and the percentage.

As can be seen in Table 1, the most frequent type of teaching used was modeling, an implicit technique, in which structures were unobtrusively embedded in discourse with no overt direction of the interlocutors' attention to them. Task and explicit feedback were the most frequent explicit techniques. Examples and grammar materials were provided the same number of times. Finally, a few students used metalinguistic instruction.

\subsubsection{Response to instruction}

Response to instruction indicates the extent to which the Polish and Chinese students followed the expected grammatical structures. Table 2 includes the definitions and frequencies of the codes.

The most frequent response to instruction was uptake, followed by lack of uptake, and, finally, attempted uptake. Within the "uptake" code, 40 instances were found in the Polish, and 19 were found in the Chinese students' emails. Nine instances of "lack of uptake" were identified in the Polish and 23 in the Chinese students' emails, whereas the division of the instances of the "attempted uptake" code was more balanced: eight in the Polish and 11 in the Chinese students' emails.

\footnotetext{
${ }^{1}$ All examples from email exchanges and the survey include students' original wording.
} 
Table 1. Types of teaching

\begin{tabular}{|c|c|c|c|c|}
\hline Code & Definition & Example & $\begin{array}{l}\text { Total } \\
\text { count } \\
(113)\end{array}$ & $\begin{array}{c}\text { Percentage } \\
(100 \%)\end{array}$ \\
\hline Modeling & $\begin{array}{l}\text { Providing carefully structured } \\
\text { model input }\end{array}$ & $\begin{array}{l}\text { I took Japanese for three years in high } \\
\text { school, and also took Chinese in college for } \\
\text { two semesters! I definitely enjoyed learning } \\
\text { all three of these languages, although } \\
\text { Korean is the one I have retained the best, } \\
\text { and also use the most often. }\end{array}$ & 60 & $53 \%$ \\
\hline Task & $\begin{array}{l}\text { Formulating a task to practice } \\
\text { grammar }\end{array}$ & $\begin{array}{l}\text { Here's the question that we would like you } \\
\text { to answer with conditional statements: } \\
\text { "What would you do if you had } 1 \text { million } \\
\text { dollars }(3,827,400 \text { Polish Zloty/6,807,700 } \\
\text { Chinese Yuan)?" }\end{array}$ & 21 & $19 \%$ \\
\hline $\begin{array}{l}\text { Explicit } \\
\text { feedback }\end{array}$ & $\begin{array}{l}\text { Commenting on NNSs' perfor- } \\
\text { mance and/or providing } \\
\text { corrective feedback }\end{array}$ & $\begin{array}{l}\text { One thing we noticed in your responses is } \\
\text { the use of the "present perfect" tense in } \\
\text { English for the intended "past simple" tense. }\end{array}$ & 13 & $12 \%$ \\
\hline Examples & $\begin{array}{l}\text { Well-structured examples to } \\
\text { illustrate the tasks }\end{array}$ & $\begin{array}{l}\text { Please tell me about your weekends using } \\
\text { past tense - for example: This past weekend, } \\
\text { I went to the mall, and bought some } \\
\text { clothes. }\end{array}$ & 7 & $6 \%$ \\
\hline $\begin{array}{l}\text { Grammar } \\
\text { material }\end{array}$ & $\begin{array}{l}\text { Attaching additional materials } \\
\text { to enrich grammar expla- } \\
\text { nation }\end{array}$ & $\begin{array}{l}\text { A chart on the order of adjectives retrieved } \\
\text { from https://www.grammar.cl/english/ } \\
\text { adjectives-word-order.htm }\end{array}$ & 7 & $6 \%$ \\
\hline $\begin{array}{l}\text { Metalinguistic } \\
\text { instruction }\end{array}$ & $\begin{array}{l}\text { Comments with grammatical } \\
\text { terminology }\end{array}$ & $\begin{array}{l}\text { Sometimes a simple sentence is all that is } \\
\text { needed. At other times it is easier to convey } \\
\text { an idea with a complex sentence, and it } \\
\text { helps to make writing sound better. It's } \\
\text { possible to combine complex and compound } \\
\text { sentences in order to convey complicated } \\
\text { ideas in a single sentence. }\end{array}$ & 5 & $4 \%$ \\
\hline
\end{tabular}

Table 2. Response to instruction

\begin{tabular}{|c|c|c|c|c|}
\hline Code & Definition & Example & $\begin{array}{l}\text { Total } \\
\text { count } \\
(110)\end{array}$ & $\begin{array}{c}\text { Percentage } \\
(100 \%)\end{array}$ \\
\hline Uptake & $\begin{array}{l}\text { Producing grammatically correct } \\
\text { output in response to modeling or } \\
\text { explicit instruction }\end{array}$ & $\begin{array}{l}\text { Its strange and mysterious. (Chinese } \\
\text { student) } \\
\text { Feedback: Remember to use an } \\
\text { apostrophe when using the word "it's" } \\
\text { when you mean "it is"! (US student) } \\
\text { Uptake: It's a raining day in the } \\
\text { morning, and becomes sunny. }\end{array}$ & 59 & $54 \%$ \\
\hline $\begin{array}{l}\text { Lack of } \\
\text { uptake }\end{array}$ & $\begin{array}{l}\text { Producing output in which there } \\
\text { are errors in the modeled/target } \\
\text { structures }\end{array}$ & $\begin{array}{l}\text { Model: You also mentioned that you like } \\
\text { to listen to music. (US student) } \\
\text { Lack of uptake: You can also listen } \\
\text { them. (Chinese student) }\end{array}$ & 32 & $29 \%$ \\
\hline $\begin{array}{l}\text { Attempted } \\
\text { uptake }\end{array}$ & $\begin{array}{l}\text { Producing output that is partly } \\
\text { correct }\end{array}$ & $\begin{array}{l}\text { Model: I'm currently a Junior at Bethel } \\
\text { university. (US student) } \\
\text { Attempted uptake: I'm second year } \\
\text { English major. (Polish student) }\end{array}$ & 19 & $17 \%$ \\
\hline
\end{tabular}


Table 3. Frequency counts of c-units containing particular grammatical structures targeted by the US students

\begin{tabular}{|c|c|c|}
\hline Techniques & Structures & Frequency \\
\hline \multirow[t]{7}{*}{ Implicit technique (modeling) } & Present simple & $23 \%$ \\
\hline & Past simple & $16 \%$ \\
\hline & Present perfect & $10 \%$ \\
\hline & Indefinite article & $9 \%$ \\
\hline & Definite article & $8 \%$ \\
\hline & Qualifiers/Intensifiers & $8 \%$ \\
\hline & Other structures & $26 \%$ \\
\hline & Total & $100 \%$ \\
\hline \multirow{4}{*}{$\begin{array}{l}\text { Explicit techniques (tasks, explicit feedback, examples, } \\
\text { grammar material, and metalinguistic instruction) }\end{array}$} & Past simple & $35 \%$ \\
\hline & Compound sentences & $14 \%$ \\
\hline & Future simple & $13 \%$ \\
\hline & Other structures & $38 \%$ \\
\hline & Total & $100 \%$ \\
\hline
\end{tabular}

\subsubsection{Grammatical structures attended to in the emails}

As already mentioned, the US participants were free to decide on the techniques and the grammatical structures. Therefore, a different selection of structures appeared in each group's discussions. The most frequent structures, which appeared across all groups, are listed in Table 3.

It can be seen that present simple and past simple tenses (used in most of the discussed topics) were most frequently targeted in the implicit modeling technique. The past simple tense and compound sentences occurred most frequently in explicit instruction (mostly in the techniques of giving tasks and examples, less frequently in metalinguistic instruction and giving feedback). Future simple appeared only in tasks and examples. Ten other structures appeared in the modeling technique and 12 in the explicit techniques.

Table 4 contains the list of structures that most frequently occurred in the Polish and Chinese participants' responses to instruction.

As can be seen, uptake embraced the same structures in both groups (with the exception of the present simple tense), with the Polish group demonstrating generally much higher levels of uptake. In the Polish group, the selection of structures in the "uptake" and "attempted uptake" codes was almost identical. The three structures in the "lack of uptake" code (i.e. articles and the present perfect tense) are typically problematic for Polish learners of English. Interestingly, a greater variation of structures was observed in the Chinese sample's "attempted uptake" and "lack of uptake" categories. Their lack of uptake also included issues like capitalization, punctuation, and contracted forms ("other structures"), pointed out by the US students as negatively influencing comprehension.

\subsubsection{Participants' opinions}

The final theme in the analysis of the emails is participants' opinions. Table 5 includes the counts for the codes.

Most opinions about L2 learning were found in the Chinese students' emails, most suggestions for effective learning in the US students' emails, opinions about telecollaboration were all positive and evenly divided across groups, and almost all (seven out of eight) self-evaluation (mostly negative) comments were provided by the Chinese students. 
Table 4. Frequency counts of c-units containing particular grammatical structures within the "uptake," "attempted uptake," and "lack of uptake" codes

\begin{tabular}{|c|c|c|c|c|}
\hline & Polish students & & Chinese students & \\
\hline \multirow[t]{6}{*}{ Uptake } & Present simple & $21 \%$ & Past simple & $4 \%$ \\
\hline & Past simple & $19 \%$ & Compound sentences & $4 \%$ \\
\hline & Compound sentences & $8 \%$ & Indefinite article & $4 \%$ \\
\hline & Indefinite article & $7 \%$ & Other structures & $14 \%$ \\
\hline & Other structures & $19 \%$ & & \\
\hline & Total & $74 \%$ & Total & $26 \%$ \\
\hline \multirow[t]{6}{*}{ Attempted uptake } & Past simple & $11 \%$ & Compound sentences & $15 \%$ \\
\hline & Indefinite article & $6 \%$ & Future simple & $15 \%$ \\
\hline & Present simple & $6 \%$ & Past simple & $13 \%$ \\
\hline & Other structures & $7 \%$ & Present simple & $13 \%$ \\
\hline & & & Other structures & $14 \%$ \\
\hline & Total & $30 \%$ & Total & $70 \%$ \\
\hline \multirow[t]{8}{*}{ Lack of uptake } & Indefinite article & $10 \%$ & Present simple & $12 \%$ \\
\hline & Present perfect & $6 \%$ & Past simple & $9 \%$ \\
\hline & Definite article & $5 \%$ & Indefinite article & $8 \%$ \\
\hline & Other structures & $4 \%$ & Future simple & $7 \%$ \\
\hline & & & Capitalization & $7 \%$ \\
\hline & & & Present perfect & $7 \%$ \\
\hline & & & Other structures & $25 \%$ \\
\hline & Total & $25 \%$ & Total & $75 \%$ \\
\hline
\end{tabular}

\subsection{Survey responses}

\subsubsection{Responses to Likert items}

Table 6 shows descriptive statistics for the individual items and total scale related to participants' opinions about the usefulness of telecollaboration for learning and teaching L2 grammar.

As can be seen in Table 6, the mean values for the whole sample exceeded the level of 4.0, which denoted "somewhat agree." The total scale mean values were identical for the US and Polish groups. The higher mean values in the Chinese group indicated their more positive responses. These tendencies were confirmed by the subsequent analyses. A Kruskal-Wallis test revealed a level of differences among the three groups closely approaching significance $(H=5.885$, $p=0.053)$. A subsequent Mann-Whitney $U$ test showed that the US $(M d n=4)$ and Polish $(M d n=4)$ students' opinions about grammar learning in telecollaboration were comparable $(U=83.00, p=0.960, r=0.15)$. The differences between the US and Chinese $(M d n=4.8$, $U=42.5, p=0.029)$ and between the Polish and Chinese $(U=45.5, p=0.044)$ students' responses in this respect were significant, which was also confirmed by the respective large $(r=0.55)$ and medium to large $(r=0.39)$ effect sizes.

In Table 7, mean and standard deviation values are shown for each item and for the total scale related to the participants' evaluation of telecollaboration as part of their training as prospective L2 teachers.

The data in Table 7 reveal that the mean score was the highest for the Chinese group and the lowest (but still approaching the level of 4.0) for the US group. The Kruskal-Wallis test indicated 
Table 5. Participants' opinions

\begin{tabular}{|c|c|c|c|c|}
\hline Code & Definition & Example & $\begin{array}{c}\text { Total } \\
\text { count } \\
(46)\end{array}$ & $\begin{array}{l}\text { Percentage } \\
(100 \%)\end{array}$ \\
\hline $\begin{array}{l}\text { Opinion about } \\
\text { L2 learning }\end{array}$ & $\begin{array}{l}\text { Students' opinions about } \\
\text { learning grammar }\end{array}$ & $\begin{array}{l}\text { (...) learning English is a boring thing. To } \\
\text { learn English, the daily necessity is to } \\
\text { remember the words. (Chinese student) }\end{array}$ & 16 & $35 \%$ \\
\hline $\begin{array}{l}\text { Opinion about } \\
\text { telecollaboration }\end{array}$ & $\begin{array}{l}\text { Evaluating its usefulness, } \\
\text { especially in relation to } \\
\text { practicing grammar }\end{array}$ & $\begin{array}{l}\text { It's truly helped me study English grammar. } \\
\text { I sometimes practice the grammer taught in } \\
\text { English class in this communicating program, } \\
\text { I can think over and correct the mistakes } \\
\text { made by me. (Chinese student) }\end{array}$ & 13 & $28 \%$ \\
\hline $\begin{array}{l}\text { Suggestions for } \\
\text { effective L2 } \\
\text { learning }\end{array}$ & $\begin{array}{l}\text { Tips for effective L2 } \\
\text { learning }\end{array}$ & $\begin{array}{l}\text { I try to find native Speakers who I can talk to, } \\
\text { but sometimes I also talk with my friends who } \\
\text { are also studying Spanish. (US student) }\end{array}$ & 9 & $20 \%$ \\
\hline Self-evaluation & $\begin{array}{l}\text { Comments about one's } \\
\text { own proficiency and/or } \\
\text { performance }\end{array}$ & $\begin{array}{l}\text { Through this experience, I just knew how poor } \\
\text { my English is. Every time I sent an email to } \\
\text { you, I have to look up the dictionary and the } \\
\text { mobile translation. (Chinese student) }\end{array}$ & 8 & $17 \%$ \\
\hline
\end{tabular}

Table 6. Descriptive statistics for learning and teaching L2 grammar in telecollaboration

\begin{tabular}{|c|c|c|c|c|c|c|c|c|}
\hline \multirow[b]{2}{*}{ Items } & \multicolumn{2}{|c|}{$\begin{array}{c}\text { Whole } \\
\text { sample } \\
(N=39)\end{array}$} & \multicolumn{2}{|c|}{ US $(n=13)$} & \multicolumn{2}{|c|}{$\begin{array}{l}\text { Polish } \\
(n=13)\end{array}$} & \multicolumn{2}{|c|}{$\begin{array}{l}\text { Chinese } \\
(n=13)\end{array}$} \\
\hline & M & $S D$ & M & $S D$ & M & $S D$ & M & $S D$ \\
\hline Providing corrective feedback online is useful. & 4.10 & 1.09 & 3.62 & 1.04 & 4.15 & 0.98 & 4.54 & 1.13 \\
\hline Receiving corrective feedback online is useful. & 4.15 & 1.10 & 3.69 & 1.11 & 4.23 & 0.93 & 4.54 & 1.13 \\
\hline $\begin{array}{l}\text { The project helped raise my sensitivity to } \\
\text { English forms. }\end{array}$ & 3.87 & 1.13 & 3.85 & 1.07 & 3.23 & 1.09 & 4.54 & 0.88 \\
\hline $\begin{array}{l}\text { Writing and receiving the emails motivated } \\
\text { me to look up the dictionary and reference books. }\end{array}$ & 3.74 & 1.23 & 3.46 & 1.27 & 3.38 & 1.39 & 4.38 & 0.77 \\
\hline $\begin{array}{l}\text { When writing the emails, I monitored my own } \\
\text { use of grammar. }\end{array}$ & 4.56 & 0.64 & 4.77 & 0.44 & 4.69 & 0.48 & 4.23 & 0.83 \\
\hline $\begin{array}{l}\text { I paid attention to the use of English structures } \\
\text { by the native and non-native speakers of English. }\end{array}$ & 4.28 & 0.79 & 4.54 & 0.66 & 4.23 & 0.60 & 4.08 & 1.04 \\
\hline Total scale & 4.12 & 0.72 & 3.99 & 0.55 & 3.99 & 0.72 & 4.38 & 0.86 \\
\hline
\end{tabular}

significant differences across groups $(H=9.501, p=0.009)$. The Mann-Whitney $U$ test revealed no difference between the US $(M d n=4)$ and Polish $(M d n=4)$ subsamples $(U=83.50, p=0.96$, $r=0.01)$. However, differences were revealed between the US and Chinese $(M d n=4.7)$ groups $(U=35.50, p=0.012)$ and between the Polish and Chinese groups $(U=30.00, p=0.004)$. Again, they were also evident in the large effect size values ( $r=0.49$ and $r=0.55$, respectively).

\subsubsection{Open-ended survey responses}

Table 8 shows the themes, example responses, and total number of responses for each theme concerning participants' suggestions for improving the telecollaboration project. Two responses included more than one theme; three responses were coded as other, a code that is not represented here. 
Table 7. Descriptive statistics for the value of telecollaboration for $L 2$ teacher training

\begin{tabular}{|c|c|c|c|c|c|c|c|c|}
\hline \multirow[b]{2}{*}{ Items } & \multicolumn{2}{|c|}{$\begin{array}{l}\text { Whole } \\
\text { sample } \\
(N=39)\end{array}$} & \multicolumn{2}{|c|}{ US $(n=13)$} & \multicolumn{2}{|c|}{$\begin{array}{l}\text { Polish } \\
(n=13)\end{array}$} & \multicolumn{2}{|c|}{$\begin{array}{l}\text { Chinese } \\
(n=13)\end{array}$} \\
\hline & $M$ & $S D$ & $M$ & $S D$ & $M$ & $S D$ & $M$ & $S D$ \\
\hline $\begin{array}{l}\text { The telecollaboration was a useful experience } \\
\text { in my teacher training. }\end{array}$ & 3.72 & 1.00 & 3.46 & 1.05 & 3.46 & 0.78 & 4.23 & 1.01 \\
\hline $\begin{array}{l}\text { I want my future students to learn about other } \\
\text { cultures via telecollaboration. }\end{array}$ & 4.23 & 1.06 & 3.69 & 1.18 & 4.31 & 0.63 & 4.69 & 1.11 \\
\hline $\begin{array}{l}\text { I will use online communication in my future } \\
\text { language teaching. }\end{array}$ & 3.95 & 0.94 & 3.62 & 1.12 & 3.92 & 0.76 & 4.31 & 0.86 \\
\hline $\begin{array}{l}\text { This project helped me understand the value } \\
\text { of culture in language teaching and learning. }\end{array}$ & 4.26 & 0.96 & 4.46 & 1.13 & 3.92 & 0.49 & 4.38 & 1.12 \\
\hline Total scale & 4.04 & 0.77 & 3.81 & 0.84 & 3.90 & 0.45 & 4.40 & 0.87 \\
\hline
\end{tabular}

Table 8. Themes from open-ended survey responses

\begin{tabular}{|c|c|c|c|c|c|}
\hline Theme & Example & Total & $\begin{array}{c}\text { US } \\
\text { students }\end{array}$ & $\begin{array}{l}\text { Polish } \\
\text { students }\end{array}$ & $\begin{array}{l}\text { Chinese } \\
\text { students }\end{array}$ \\
\hline Platform/modality & $\begin{array}{l}\text { I would prefer to use other platforms such us } \\
\text { Facebook or Instagram. E-mails are too strict. }\end{array}$ & 10 & 2 & 6 & 2 \\
\hline Accountability & $\begin{array}{l}\text { Maybe make sure the other students are required } \\
\text { to answer for class so we get more responses. }\end{array}$ & 6 & 4 & 2 & - \\
\hline Topics & $\begin{array}{l}\text { There can be more content related to the culture } \\
\text { of different countries, such as customs, and some } \\
\text { popular expressions can be exchanged ... }\end{array}$ & 5 & - & 1 & 4 \\
\hline $\begin{array}{l}\text { Expectations/ } \\
\text { Awareness }\end{array}$ & $\begin{array}{l}\text { Hope we can correct each other, and exchange our } \\
\text { experiences. }\end{array}$ & 4 & 3 & 1 & - \\
\hline Grouping & $\begin{array}{l}\text { I think it would be helpful if it was more of a } \\
\text { one-on-one communication instead of having two } \\
\text { English speakers with two Chinese students and } \\
\text { two Polish students. }\end{array}$ & 3 & 1 & 1 & 1 \\
\hline
\end{tabular}

Overall, students commented most often about the "platform/modality." Rather than using email, they suggested chats, video calls, Facebook, or Instagram for communication. In fact, all students indicated that email was not the preferred form of communication. As one student explained, "Sometimes it takes people a lot of time to respond, it takes away part of the natural aspect of the conversation."

"Accountability" was also important to students, especially the US participants, with comments such as, "Have accountability for students to respond. Perhaps due dates to responses, or set aside certain window of time to converse." Five students, mostly Chinese, commented on the "topics" discussed in the email exchanges each week. For instance, one student had a suggestion for the types of topics to include, "We can divide the cultures into ancient and modern parts."

"Expectations/awareness" captured students' thoughts about providing and receiving feedback on grammar. One US student commented, "It was difficult for our class to feel comfortable to give them feedback. I think we were too worried about being rude." Conversely, one Polish student wrote, "Next time, I would like to get some more feedback cause I didn't get much." "Grouping" included two suggestions to have smaller groups and one suggestion to "attract more students to participate in this project." 


\section{Discussion}

The first research question addressed the grammar teaching techniques and responses that they elicited. Although various techniques along the implicit-explicit continuum were detected in the email exchanges, the implicit technique of modeling was most frequently employed, which was probably stimulated by the communicative orientation of the exchanges. This practice is in accordance with the current recommendations for embedding instruction in meaning-rich contexts, derived from the interactionist approaches, according to which interpersonal interaction provides learners with evidence of how structures are used and draws their attention to L2 features (LarsenFreeman, 2014; Long, 1996). The participants' reliance on implicit modeling is consistent with the results reported in other research (e.g. Samburskiy \& Quah, 2014; Ware \& O'Dowd, 2008), in which less obtrusive options in providing CF were also preferred. It is likely that a preference for less explicit techniques indicated a politeness strategy. Such an attitude, which indicates sensitivity to contextual considerations, not only linguistic but also social, was revealed in the studies by Ware and O'Dowd (2008), Jin (2013), and Akiyama (2017). With reference to sociocultural theory, it points to the positioning of participants during interaction and reveals their emerging, sometimes conflicting, identities and roles (e.g. L2 experts and collaborators/peers) (Helm, 2018).

It could be seen that the input provided through modeling, examples, and explicit feedback contained different types of enhancement (Sharwood Smith, 2014): perceptual (e.g. "Entertainment will look like ..."); conceptual, as explanations were provided (e.g. "in English, adjectives usually come before nouns"); and affective, as the content was relevant to the students, often humorous (e.g. "I love hearing your unique holiday celebration of 'Wet Monday"'). They attracted the students' attention, which was admitted in the survey, and which is accordant with the interactionist approach of the facilitative role of positive evidence in learner-directed input (e.g. Gass, 1997). The enhancements, the topics and tasks to elicit the use of certain language forms, as well as the time available to focus on the input and one's own output, can be assumed to be the factors contributing to uptake in the students' production (as also discussed by Heift \& Vyatkina, 2017; Ware \& Pérez Cañado, 2007). The considerable differences in the levels of uptake between the Polish and the Chinese students resulted from the different proficiency levels, which is in line with VanPatten's (1990) conclusion that lower-proficiency learners focus on form only when processing the meaning does not block their input processing resources, and Li's study (2014), which revealed less uptake, especially in response to recasts, in lower-proficiency participants.

The selection of structures targeted in the instruction (Research Question 2) closely aligned with the communicative orientation of the exchanges. Basic tenses, articles, and qualifiers were modeled by the US students in their discussion of the topics. The forms selected for explicit instruction varied across groups and were used to give the communicative tasks a formorientation (e.g. "I would like you all to try using past tense, and talk about what you did the past week!"). Apart from that, the structures targeted for explicit CF, examples, and metalinguistic instruction usually reflected the EFL learners' needs and problems noticed by the US students. Moreover, another finding was that the erroneous use of forms ("lack of uptake") reflected the cross-lingual differences between the Polish and Chinese students. The structures that do not exist in Polish, present perfect tense and articles, appeared to be particularly resistant to instruction; the Chinese students demonstrated consistent challenges, regardless of the type of instruction received, with the correct use of punctuation, capitalization, and apostrophes due to considerable differences in the Chinese and English writing systems.

In relation to the third research question, as was illustrated by the emails and the survey responses, the participants' perceptions about the value of telecollaboration for learning L2 grammar were highly positive. In terms of grammar instruction, it was a beneficial experience in the use of English as a lingua franca at both productive and receptive levels, which is important for both NS and NNS users of English. However, it was the Chinese students who expressed the 
most positive opinions, which can be linked to the Chinese students' accounts of their EFL learning experience at school as highly form-oriented, boring, and hence not useful for their overall communicative needs. This approach has been confirmed in several publications (e.g. Zheng, 2015), according to which L2 teaching in China is still predominantly teacher-centered and rule-oriented. Valuing the opportunity to attend to both meaning and grammar in the interactions, some of the participants wanted even more focus on form in the exchanges, and voiced complaints about having received too little CF from their US peers. The positive attitudes toward a focus on form in telecollaboration are congruent with Vinagre and Muñoz's (2011) findings. In our study, this finding may also indicate that the NNS participants accepted their learner role, thus in a way co-constructing the power asymmetry of the exchanges.

The participants' evaluation of telecollaboration as part of their teacher training was also highly positive. The US students, who acted as teachers and leaders in the project, got experience with providing instruction in an innovative communicative context. The Polish and Chinese participants, who acted as learners, still benefited in terms of their teaching competence through their active participation, paying attention to their own and others' output, and reflecting on the utility of telecollaborative practice. The involvement in online exchanges with NS and NNS peers from other countries helped them realize how useful such practice can be for learners. It can be thus assumed that this experience was a form of cognitive apprenticeship (Dooly \& Sadler, 2013) for all pre-service teacher participants, even those who performed the role of learners in the telecollaboration. Most of them expressed a willingness to implement online communication in their future teaching, which is a promising prospect and an indication of their opening up to CMC as an educational option. This aligns with Dooly and Sadler (2020), who see a link between telecollaboration experience in teacher training and teachers' readiness to implement such instructional practices in their own teaching.

The students' critique of the project focused on the organization of such exchanges. They mentioned the limitations of email, and formulated recommendations (sometimes contradictory) about the size of the groups and the need for stimulating more equal and regular participation. The US students' criticism of the low accountability of some NNS and their often unfulfilled expectations to give more instruction resulted from their managerial role in the project. An unequal power distribution, which makes the NS assume a "didactic voice," may result in the NNSs' reluctance to participate for fear of being evaluated by their limited L2 competence (Helm, 2018; Liddicoat, 2016). Apart from indicating the perceived weaknesses of this telecollaboration, the students' reflections revealed their mindful and commonsensical approach toward such practices, contributing to their expertise as future educators.

In fact, the students' suggestions point to certain limitations of the study, among which the use of email as the only medium of interaction should be listed. Another limitation is that the Chinese group was not directly supervised by a faculty member at their university (it was monitored at a distance by the second author). Moreover, the NNS participants could have been more involved in the selection of topics for the interactions, which would have at least partly balanced the asymmetry in the design of the exchanges and influenced the dynamics of the students' participation.

\section{Conclusions and implications}

The study provided evidence on the grammar teaching and learning behavior demonstrated by pre-service teachers from three different cultural and educational settings in a multinational telecollaborative project. Although a range of grammar instruction techniques were identified in the email exchanges, implicit, non-obstructive techniques dominated, which gives further support to telecollaboration being a venue for primarily meaning- and discourse-oriented form-focused instruction. The grammatical categories targeted by the NS participants aligned with 
the discussed topics, and the accuracy of L2 use in the NNS students' output revealed their proficiency and linguistic background. The benefits of the telecollaboration were evident both in the high volume of uptake and in the positive perceptions of the value of this type of activity for learning L2 grammar and for the development of teaching skills.

The results of this study lead to some implications for L2 teacher education. Telecollaboration is a relevant element of instructing pre-service teachers in how to focus on form in communication- and interaction-embedded activities. Moreover, a multinational telecollaborative project orients pre-service teachers toward noticing cross-linguistic differences among learners from various linguistic backgrounds and hence prepares them to offer adequate instruction. A related implication concerns using multinational telecollaborative settings to enhance future teachers' critical multilingual awareness, which is increasingly considered an important part of 21 st-century L2 teachers' competence. This can be done through immersing teachers in multilingual contexts, with the use of translanguaging and an analysis of literacy practices in the particular cultures. Comparing grammatical structures and exploring form-meaning-use links within these practices could be a viable option in teacher education programs.

Acknowledgements. We would like to thank the students from the three institutions who volunteered to participate in this study.

Ethical statement. This study was carried out in accordance with the ethical standards of the responsible committees on human experimentation in the three institutions. Oral consent was obtained from participants who volunteered in the study. Anonymity of the participants' responses was preserved. There are no conflicts of interest.

\section{References}

Akiyama, Y. (2017) Learner beliefs and corrective feedback in telecollaboration: A longitudinal investigation. System, 64: 58-73. https://doi.org/10.1016/j.system.2016.12.007

Angelova, M. \& Zhao, Y. (2016) Using an online collaborative project between American and Chinese students to develop ESL teaching skills, cross-cultural awareness and language skills. Computer Assisted Language Learning, 29(1): 167-185. https:// doi.org/10.1080/09588221.2014.907320

Chen, W.-C. \& Eslami, Z. (2013) Focus on form in live chats. Educational Technology \& Society, 16(1): 147-158.

Crookes, G. (1990) The utterance, and other basic units for second language discourse analysis. Applied Linguistics, 11(2): 183-199. https://doi.org/10.1093/applin/11.2.183

Dooly, M. (2017) Telecollaboration. In Chapelle, C. A. \& Sauro, S. (eds.), The handbook of technology and second language teaching and learning. Hoboken: John Wiley \& Sons, 169-183. https://doi.org/10.1002/9781118914069.ch12

Dooly, M. \& O'Dowd, R. (2018) Telecollaboration in the foreign language classroom: A review of its origins and its application to language teaching practice. In Dooly, M. \& O’Dowd, R. (eds.), In this together: Teachers' experiences with transnational, telecollaborative language learning projects. Bern: Peter Lang, 11-34.

Dooly, M. \& Sadler, R. (2013) Filling in the gaps: Linking theory and practice through telecollaboration in teacher education. ReCALL, 25(1): 4-29. https://doi.org/10.1017/S0958344012000237

Dooly, M. \& Sadler, R. (2020) “If you don't improve, what's the point?" Investigating the impact of a "flipped” online exchange in teacher education. ReCALL, 32(1): 4-24. https://doi.org/10.1017/S0958344019000107

Dussias, P. E. (2006) Morphological development in Spanish-American telecollaboration. In Belz, J. A. \& Thorne, S. L. (eds.), Internet-mediated intercultural foreign language education. Boston: Thomson, Heinle, 121-146.

Ellis, R. (2014) Grammar teaching for language learning. Babylonia, 2(14): 10-15.

The EVALUATE Group (2019) Evaluating the impact of virtual exchange on initial teacher education: A European policy experiment. Voillans: Research-publishing.net. https://doi.org/10.14705/rpnet.2019.29.9782490057337

Gass, S. M. (1997) Input, interaction, and the second language learner. Mahwah, NJ: Lawrence Erlbaum Associates.

Heift, T. \& Vyatkina, N. (2017) Technologies for teaching and learning L2 grammar. In Chapelle, C. A. \& Sauro, S. (eds.), The handbook of technology and second language teaching and learning. Hoboken: John Wiley \& Sons, 26-44. https://doi.org/10. 1002/9781118914069.ch3

Helm, F. (2018) Emerging identities in virtual exchange. Voillans: Research-publishing.net. https://doi.org/10.14705/rpnet. 2018.25.9782490057191

Jin, L. (2013) Language development and scaffolding in a Sino-American telecollaborative project. Language Learning \& Technology, 17(2): 193-219. http://doi.org/10125/44330

Johnson, K. E. (2009) Second language teacher education: A sociocultural perspective. New York: Routledge. https://doi.org/10. $4324 / 9780203878033$ 
Johnson, K. E. \& Golombek, P. R. (2020) Informing and transforming language teacher education pedagogy. Language Teaching Research, 24(1): 116-127. https://doi.org/10.1177/1362168818777539

Kurek, M. \& Müller-Hartmann, A. (2019) The formative role of teaching presence in blended virtual exchange. Language Learning \& Technology, 23(3): 52-73. https://doi.org/10125/44696

Lantolf, J. P., Thorne, S. L. \& Poehner, M. E. (2015) Sociocultural theory and second language development. In VanPatten, B. \& Williams, J. (eds.), Theories in second language acquisition: An introduction (2nd ed.). New York: Routledge, $207-226$.

Larsen-Freeman, D. (2014) Teaching grammar. In Celce-Murcia, M., Brinton, D. M. \& Snow, M. A. (eds.), Teaching English as a second or foreign language (4th ed.). Boston: National Geographic Learning, 256-270.

Larson-Hall, J. (2010) A guide to doing statistics in second language research using SPSS. New York: Routledge. https://doi.org/ $10.4324 / 9780203875964$

Li, S. (2014) The interface between feedback type, L2 proficiency, and the nature of the linguistic target. Language Teaching Research, 18(3): 373-396. https://doi.org/10.1177/1362168813510384

Liddicoat, A. J. (2016) Native and non-native speaker identities in interaction: Trajectories of power. Applied Linguistics Review, 7(4): 409-429. https://doi.org/10.1515/applirev-2016-0018

Long, M. H. (1996) The role of the linguistic environment in second language acquisition. In Ritchie, W. C. \& Bhatia, T. K. (eds.), Handbook of second language acquisition. New York: Academic Press, 413-468. https://doi.org/10.1016/B978012589042-7/50015-3

Lyster, R. \& Ranta, L. (1997) Corrective feedback and learner uptake: Negotiation of form in communicative classrooms. Studies in Second Language Acquisition, 19(1): 37-66. https://doi.org/10.1017/S0272263197001034

Merriam, S. B. \& Tisdell, E. J. (2016) Qualitative research: A guide to design and implementation (4th ed.). San Francisco, CA: Jossey-Bass.

Mishra, P. \& Koehler, M. J. (2006) Technological pedagogical content knowledge: A framework for teacher knowledge. Teachers College Record, 108(6): 1017-1054. https://doi.org/10.1111/j.1467-9620.2006.00684.x

O’Dowd, R. (2015) The competences of the telecollaborative teacher. The Language Learning Journal, 43(2): 194-207. https:// doi.org/10.1080/09571736.2013.853374

O'Dowd, R. (2018) From telecollaboration to virtual exchange: State-of-the-art and the role of UNICollaboration in moving forward. Journal of Virtual Exchange, 1: 1-23. https://doi.org/10.14705/rpnet.2018.jve.1

Patton, M. Q. (2002) Qualitative research and evaluation methods (3rd ed.). Thousand Oaks, CA: SAGE.

Rienties, B., Lewis, T., O’Dowd, R., Rets, I. \& Rogaten, J. (2020) The impact of virtual exchange on TPACK and foreign language competence: Reviewing a large-scale implementation across 23 virtual exchanges. Computer Assisted Language Learning. Advance online publication. https://doi.org/10.1080/09588221.2020.1737546

Samburskiy, D. \& Quah, J. (2014) Corrective feedback in asynchronous online interaction: Developing novice online language instructors. CALICO Journal, 31(2): 158-178. https://doi.org/10.11139/cj.31.2.158-178

Sauro, S. (2009) Computer-mediated corrective feedback and the development of L2 grammar. Language Learning \& Technology, 13(1): 96-120.

Sauro, S. (2013) The cyber language exchange: Cross-national computer-mediated interaction. In McDonough, K. \& Mackey, A. (eds.), Second language interaction in diverse educational contexts. Amsterdam: John Benjamins, 129-146. https://doi. org/10.1075/1llt.34.11ch7

Schmidt, R. W. (1990) The role of consciousness in second language learning. Applied Linguistics, 11(2): 129-158. https://doi. org/10.1093/applin/11.2.129

Sharwood Smith, M. (2014) Possibilities and limitations of enhancing language input: A MOGUL perspective. In Benati, A., Laval, C. \& Arche, M. J. (eds.), The grammar dimension in instructed second language learning. London: Bloomsbury, 36-57.

VanPatten, B. (1990) Attending to form and content in the input: An experiment in consciousness. Studies in Second Language Acquisition, 12(3): 283-301. https://doi.org/10.1017/S0272263100009177

Vinagre, M. (2017) Developing teachers' telecollaborative competences in online experiential learning. System, 64: 34-45. https://doi.org/10.1016/j.system.2016.12.002

Vinagre, M. \& Muñoz, B. (2011) Computer-mediated corrective feedback and language accuracy in telecollaborative exchanges. Language Learning \& Technology, 15(1): 72-103. https://doi.org/10125/44238

Ware, P. \& O’Dowd, R. (2008) Peer feedback on language form in telecollaboration. Language Learning \& Technology, 12(1): 43-63. https://doi.org/10125/44130

Ware, P. D. \& Pérez Cañado, M. L. (2007) Grammar and feedback: Turning to language form in telecollaboration. In O’Dowd, R. (ed.), Online intercultural exchange: An introduction for foreign language teachers. Clevedon: Multilingual Matters, 107-126. https://doi.org/10.21832/9781847690104-008

Zheng, H. (2015) Teacher beliefs as a complex system: English language teachers in China. Cham: Springer. https://doi.org/10. 1007/978-3-319-23009-2 


\section{Appendix: Topics in the email exchanges}

Language learning profiles; favorite music; academic calendars/school breaks; national holidays; national cuisines; eating habits; family structures; your hometown/neighborhood; environmental problems/climate change; favorite or recent movies and television shows; end-of-the-school-year traditions; past and present hobbies; favorite aspects of your university; reasons for learning English; weather, climate, and geography; history and tradition; academic and daily routines; interpretation of a poem.

\section{About the authors}

Aleksandra Wach is an associate professor in the Faculty of English, Adam Mickiewicz University in Poznań, Poland. Her research interests include foreign language teacher training, teaching L2 grammar, technology in L2 learning and teaching, and the role of the learners' native language in L2 instruction.

De Zhang has been an adjunct faculty member in the TESOL program at Bethel University and M.A. in ESL program at Saint Mary's University of Minnesota. Her major research interests include telecollaboration for language teaching and teacher education.

Kristen Nichols-Besel is the multilingual academic support coordinator and writing center faculty tutor in the Academic Enrichment and Support Center at Bethel University, Minnesota. Her research interests include academic support for multilingual learners, writing center pedagogy, and young adult literature.

Author ORCiD. (D) Aleksandra Wach, https://orcid.org/0000-0003-3341-6347

Author ORCiD. (D) De Zhang, https://orcid.org/0000-0002-1311-2226

Author ORCiD. (D) Kristen Nichols-Besel, https://orcid.org/0000-0003-0008-3574 